\title{
フェライト焼結体の曲げ強度に及ぼす残留カーボンの影響
}

\author{
青木 卓也，村瀬 琢，野村 武史 \\ TDK 珠基礎材料研究所， 个285-8588 千葉県成田市南羽鳥字松ヶ下 570-2.
}

\section{Effect of Residual Carbon on Bending Strength of Sintered Ferrite}

\author{
Takuya Aoki, Taku Murase and Takeshi Nomura \\ Materials Research Center, TDK Corporation, 570-2 Matsugashita Minamihatori, Narita 286-8588.
}

Received October 12, 2000

\begin{abstract}
SYNOPSIS
The bending strength of sintered ferrites has been studied for $\mathrm{MgCuZn}_{-}, \mathrm{NiCuZn-}$, and $\mathrm{MnZn}$-ferrites. It has been found that residual carbon content affects bending strength of these sintered ferrites. The sintered ferrites containing much residual carbon lower the bending strength. It is considered that PVA, which is added when the ferrite powder is granulated, remains as residual carbon in sintered ferrite after sintering. Control of the residual carbon content of sintered ferrite is one of the most important factors for obtaining high performance ferrite.
\end{abstract}

KEY WORDS

sintered ferrite, residual carbon, bending strength

\section{1 緒 言}

電子機器の小型化・薄型化に伴い,フェライト部品も同様 に小型化・薄型化が求められている。 それに従い製品として の信頼性を保つため機械的強度の高いフェライトが要求され ている. 機械的強度を向上させるためにホットプレスを用い たり ${ }^{1)}$ ，種々の添加物を添加する ${ }^{2-4)}$ などの方法が知られてい る.また，セラミックス多結晶体の機械的性質は，セラミッ クスを構成する結晶粒子や気孔などの微細構造要素およびそ れらの量比, 形態, 分布状態をはじめとする種々のパラメー 夕に影響される.これらパラメー夕は製造プロセスにおける 温度・圧力・雾囲気などにより大きく変化するっ。機械的強度 を向上させるためには高い焼結密度が必要であり，そのため には成形密度を高くすることが重要である.高い成形密度を 得るためには高度な造粒, 成形技術が必要である ${ }^{6,7}$. 一般に フェライト焼結体の製造では造粒時にPVAなどの有機系バイ ンダーが用いられる.この有機系バインダーは焼成後も残留 カーボンとして焼結体中に微量に存在するものと思われる. また，その残留カーボン量は焼成条件により変化することが 予想される.この残留カーボンがフェライト焼結体の曲げ強 度に及ほす影響について検討した報告はほとんどない。本研 究ではフェライト焼結体の機械的強度の向上を目的として
$\mathrm{MgCuZn}$ フェライト, $\mathrm{NiCuZn}$ フェライトおよび $\mathrm{MnZn}$ フェラ イトについて微細構造要素と機械的強度の関係を調べる過程 でフェライト焼結体中の残留カーボン量と曲げ強度の関係に おいて新しい知見が得られたので報告する。

\section{2 実験方法}

$\mathrm{MgCuZn}$ フェライトにおいては高純度の $\mathrm{Fe}_{2} \mathrm{O}_{3}, \mathrm{MgO}, \mathrm{CuO}$, $\mathrm{ZnO}$ をそれぞれ 48.0, 19.0, 7.0, 26.0mol\%になるように秤量し た.これらの粉体を鎆鉄製ボールミルに投入し分散媒に水を 用いて16時間湿式混合した後，乾燥した. 得られた混合粉を 空気中にて $900^{\circ} \mathrm{C} て ゙ 2$ 時間仮焼成を行った後，この仮焼粉を 鋼鉄製ボールミルで16時間粉砕した. 得られたフェライト粉 末に $6 \% \mathrm{PVA}$ 水溶液を $10 \mathrm{wt} \%$ 加え，顆粒を作製した。そ後 $98 \mathrm{MPa}$ の圧カでトロイダル形状 (外径 $24 \mathrm{~mm}$, 内径 $12 \mathrm{~mm}$, 厚 さ $6 \mathrm{~mm})$ に成形し，空気中にて $1020 \sim 1050^{\circ} \mathrm{C} て ゙ 3$ 時間焼成し た. その際，Air 流量を $200 \sim 3000 \mathrm{ml} / \mathrm{min}$. の範囲で変化させ た. 焼結体中の残留カーボン量は赤外線吸収法をその他の微 量成分はICP を用いて分析した. 赤外線吸収法およびICPに よる分析値の測定誤差は $5 \%$ 程度である.また, 元素濃度分布 は電子線プロープマイクロアナライザー(EPMA)により解析 した. 焼結体の微細構造については試料を鏡面研磨後,フッ 
酸水溶液で腐食を施し，内部組織を光学顕微鏡で観察した。 また，画像解析により内部組織の平均結晶粒径を調へた。曲 げ強度用のサンプルは得られたフェライト顆粒を $98 \mathrm{MPa}$ の圧 力で $5 \times 5 \times 50 \mathrm{~mm}$ の角型形状に成形し，Air 流量を 200 3000 $\mathrm{ml} / \mathrm{min}$.の範囲で変化させて $1020^{\circ} \mathrm{C} て ゙$ 焼成した. 焼結体の曲げ 強度は3 点曲け試験法を用い評価した. さらに NiCuZnフェラ イトにおいては $\mathrm{Fe}_{2} \mathrm{O}_{3}, \mathrm{NiO}, \mathrm{CuO}, \mathrm{ZnO}$ ぞれぞれ49.0, 16.0, 7.0, $28.0 \mathrm{~mol} \%$ の組成物を用いて空気中にて $1100^{\circ} \mathrm{C} て ゙$ 焼成をし，同様 な検討を行った. $\mathrm{MnZn}$ フェライトにおいては $\mathrm{Fe}_{2} \mathrm{O}_{3}, \mathrm{MnO}, \mathrm{ZnO}$ がそれぞれ 53.6, 36.2, 10.2 mol\%の組成物を用いて酸素分圧を

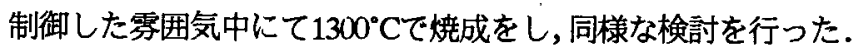

\section{3 実験結果および考察}

3.1 焼結密度および粒径と曲げ強度の関係

一般に焼結密度が高いほどかつ粒径が小さいほど曲げ強度 が高くなることが知られている. Fig.1に焼結密度と曲げ強度 の関係を示す，焼成温度を変化させることにより焼結密度の 異なるサンプルを得た，狫結密度が低い領域では焼結密度と 曲げ強度の相関が強くなっているが，焼結密度が高く理論密 度 $\left(5.05 \mathrm{Mg} / \mathrm{m}^{3}\right)$ に近い領域においては相関が弱いことが分か る. 次に烧結密度と曲げ強度の相関が弱い焼結密度が $4.85 〜$ $4.90 \mathrm{Mg} / \mathrm{m}^{3}$ の範囲にある試料について,その平均粒径と曲げ強 度の関係を調べた。結果を Fig.2に示す. 粒径が小さいほど曲 げ強度が高くなる傾向がある。しかしながら，平均粒径およ び焼結密度がほほ同等であるにもかかわらず曲げ強度が大き く異なる現象が見られる.この原因として焼結体の粒度分布， 結晶粒子の組成, 気孔の形状および分布, 微量成分量が異な ることが考えられる。

2.2 残留カーボン量と曲げ強度の関係

佬結密度および粒径がほぼ同じであるにもかかわらず，機

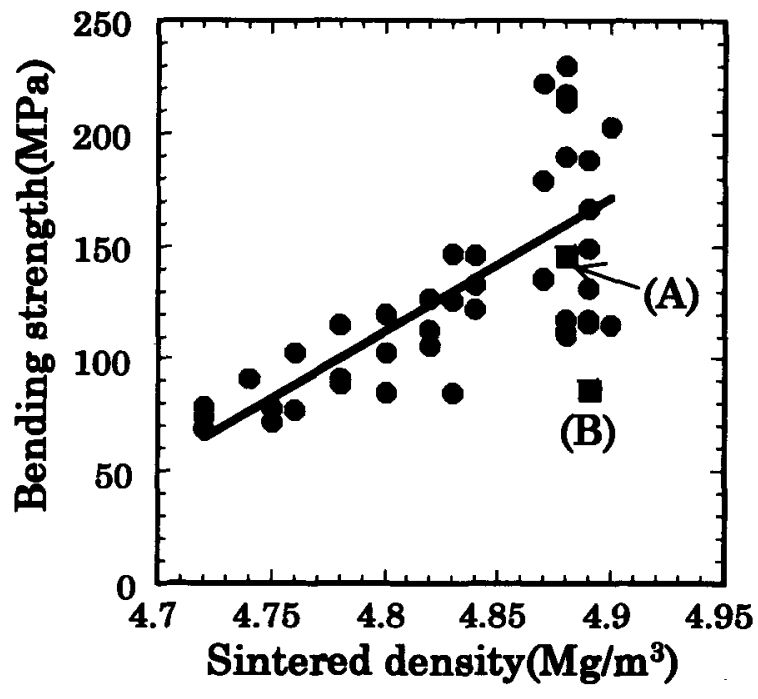

Fig.1 Relationship between sintered density and bending strength of sintered $\mathrm{MgCuZn}$ ferrites. Samples pointed in (A) and (B) in the diagram are subjected for further detailedexaminations.
械的強度が異なる試料 AとBについてそれそれ詳細な解析を 行った. 試料 A, B の曲げ強度および平均粒径を Table 1に，微 細構造および粒度分布を Fig.3,4に示す. 平均粒径, 気孔の形 状および分布に大きな違いがないことが分かる．また，粒度 分布にも大きな違いがないことが分かる. 今回の実験で用い た $\mathrm{MgCuZn}$ フェライトは $\mathrm{Fe}_{2} \mathrm{O}_{3}$ が $50 \mathrm{~mol} \%$ 以下であり, $\mathrm{Mg}$ お よび Cuの偏析が予想される,9. それそれの試料について $\mathrm{Mg}$ およびCuの偏析状態を調べるためEPMA を用いて焼結体の 元素濃度分布を調へた. 結果を Fig.5に示す. 各元素の濃度分 布に大きな違いがないことが分かる. 試料 A，Bの焼成時にお ける Air 流量はそれそれ $3000 \mathrm{ml} / \mathrm{min}$. および $50 \mathrm{ml} / \mathrm{min}$.であり 異なっている. そのため焼結体中の揮発しやすい微量成分を 中心にその含有量が異なっている可能性がある. 分析結果を Table 2に示す.ほとんどの微量成分量は同等であるが強度の 低いサンプルは高いサンプルと比べCが約 2 倍多いことが分 かる.そこで焼結密度が $4.85 \sim 4.90 \mathrm{Mg} / \mathrm{m}^{3}$ の範囲にある試料に ついてその残留カーボン量を分析し, 残留カーボン量と曲げ 強度の関係を調べた. 結果を Fig.6に示す. 残留カーボン量が 多いほど曲げ強度が低下しており，残留カーボン量と曲げ強 度に大きな相関があることが分かる.NiCuZnフェライトにお いて焼結密度が $5.0 \mathrm{Mg} / \mathrm{m}^{3}$ 付近かつ粒径がほぼ同等なサンプル

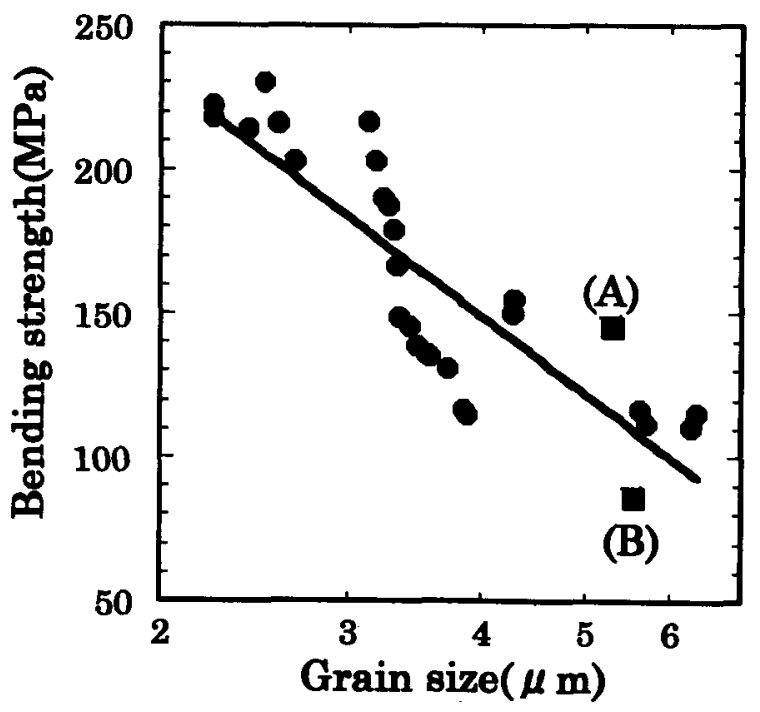

Fig.2 Relationship between grain size and bending strength of sintered $\mathrm{MgCuZn}$ ferrites. Samples pointed in (A) and (B) in the diagram are further examined, the data of which appear in Table 1 and 2, and Fig.3 Fig.5.

Table 1 Bending strength and average grain size of a sintered $\mathrm{MgCuZn}$ ferrites.

\begin{tabular}{|c|c|c|}
\hline Sample & $\begin{array}{c}\text { (MPa) } \\
\text { Bending strength }\end{array}$ & $\begin{array}{c}(\mu \mathrm{m}) \\
\text { Average grain size }\end{array}$ \\
\hline $\mathbf{A}$ & 146 & 5.28 \\
\hline B & 86 & 5.53 \\
\hline
\end{tabular}



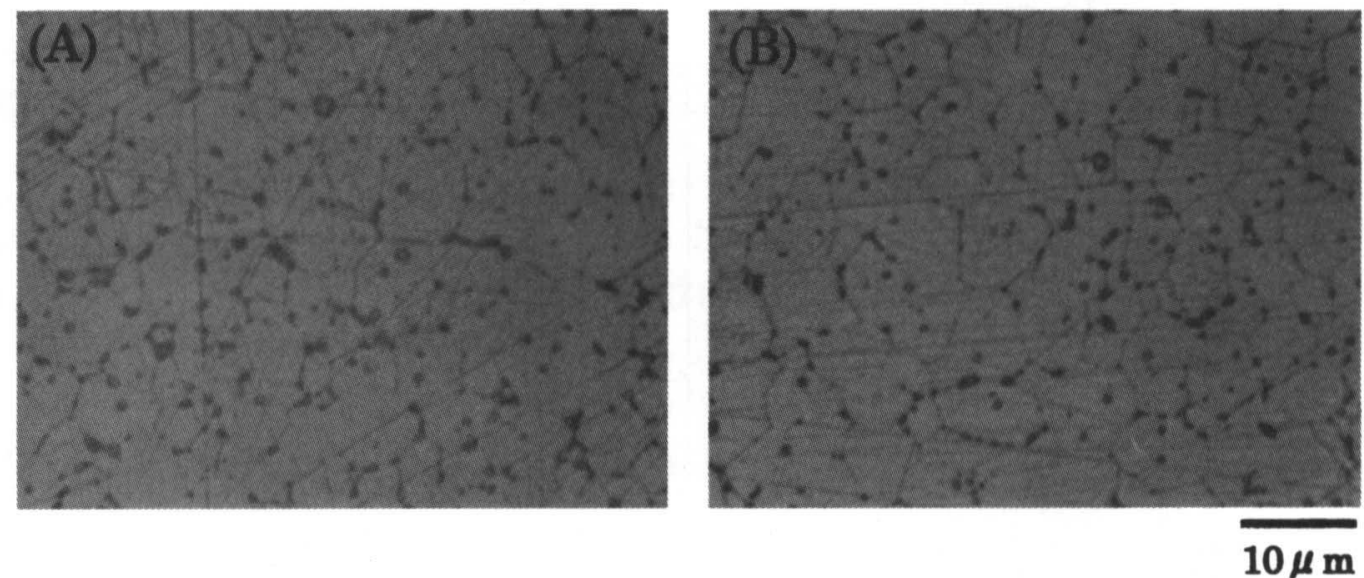

Fig.3 Microstructures of sintered MgCuZn ferrites.
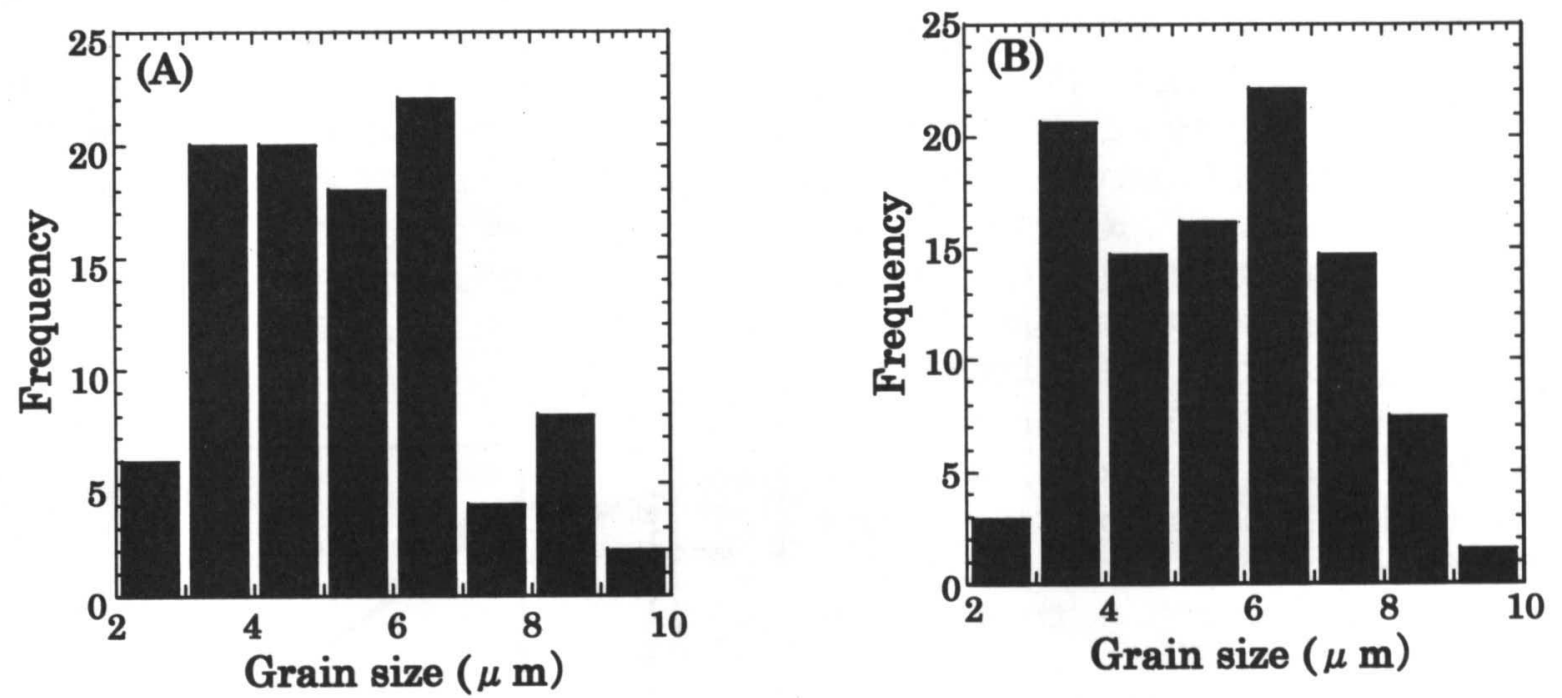

Fig.4 Distribution of grain size of sintered $\mathrm{MgCuZn}$ ferrites.

Fe

$\mathrm{Mg}$

$\mathrm{Cu}$

Zn

(A)

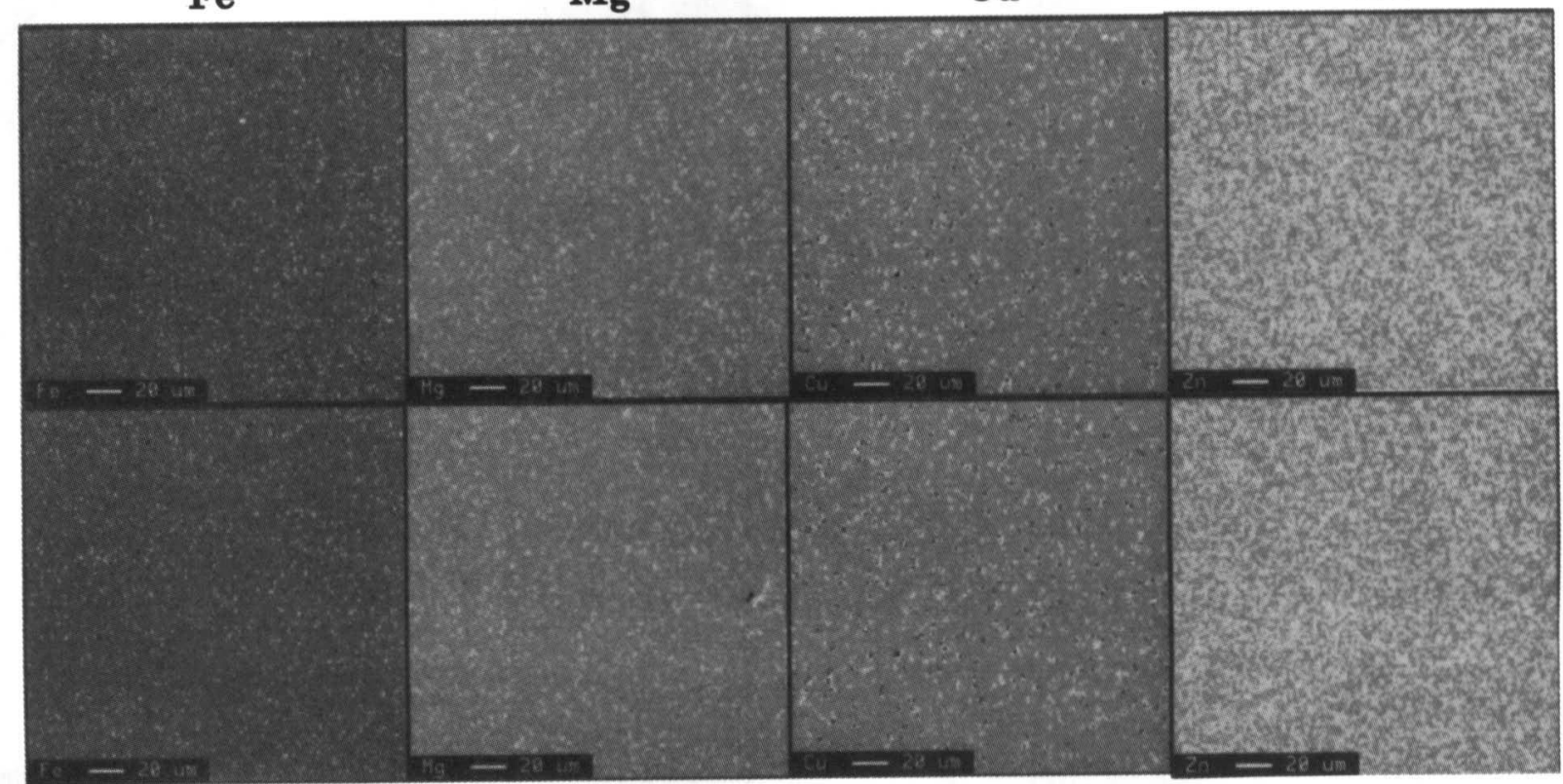

(B)

Measured area: $200 \times 200 \mu \mathrm{m}$

Fig.5 EPMA image of sintered MgCuZn ferrites. 
Table 2 Impurity contents of sintered $\mathrm{MgCuZn}$ ferrites determined by ICP analysis.

\begin{tabular}{ccccccccccccc}
\hline & \multicolumn{1}{c}{ (ppm) } \\
Sample & B & Al & Si & P & Ca & Cr & Co & Na & K & S & Cl & C \\
\hline A & 0 & 7 & 67 & 7 & 40 & 169 & 16 & 12 & 4 & 38 & 3 & 32 \\
B & 2 & 6 & 61 & 6 & 37 & 170 & 14 & 15 & 6 & 37 & 4 & 58 \\
\hline
\end{tabular}

について残留カーボン量と曲げ強度の関係を調ベた．結果を

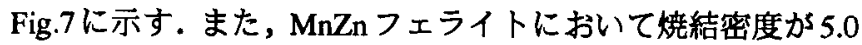
$\mathrm{Mg} / \mathrm{m}^{3}$ 付近かつ粒径がほぼ同等なサンプルについて残留カー ボンと曲げ強度の関係を調べた.その結果を Fig.8に示す. $\mathrm{NiCuZn}$ フェライトおよび $\mathrm{MnZn}$ フェライトともに $\mathrm{MgCuZn}$ フェライトと同様に残留カーボン量が多いほど曲げ強度が低

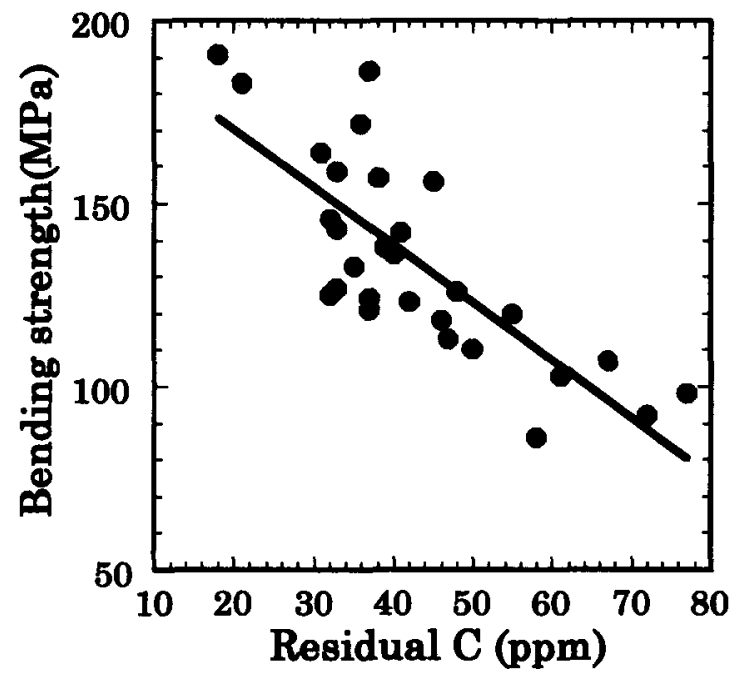

Fig.6 Relationship between bending strength and residual $\mathrm{C}$ of sintered $\mathrm{MgCuZn}$ ferrites.

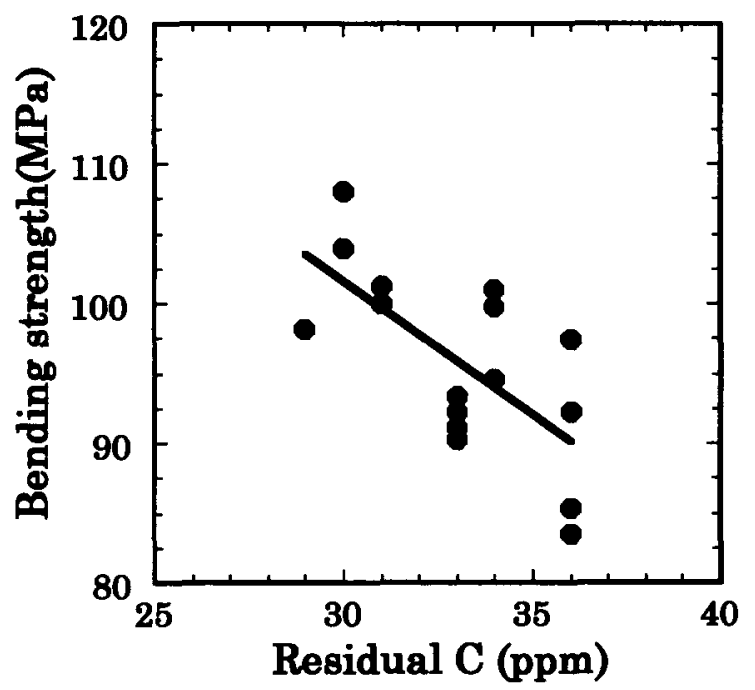

Fig.7 Relationship between bending strength and residual $\mathrm{C}$ of sintered NiCuZn ferrites.
下し，残留カーボン量と曲げ強度に大きな相関があることが 分かった。しかしながら，これら三種のフェライト焼結体で 残留するカーボン量が同じ程度でも，曲げ強度の值が異なっ ている。これは $\mathrm{MgCuZn,} \mathrm{NiCuZn,} \mathrm{MnZn} \mathrm{フェライトそれそれれ}$ の組成, 微量成分量, 焼成温度およひ微細構造が大きく異な るためと考えられる。

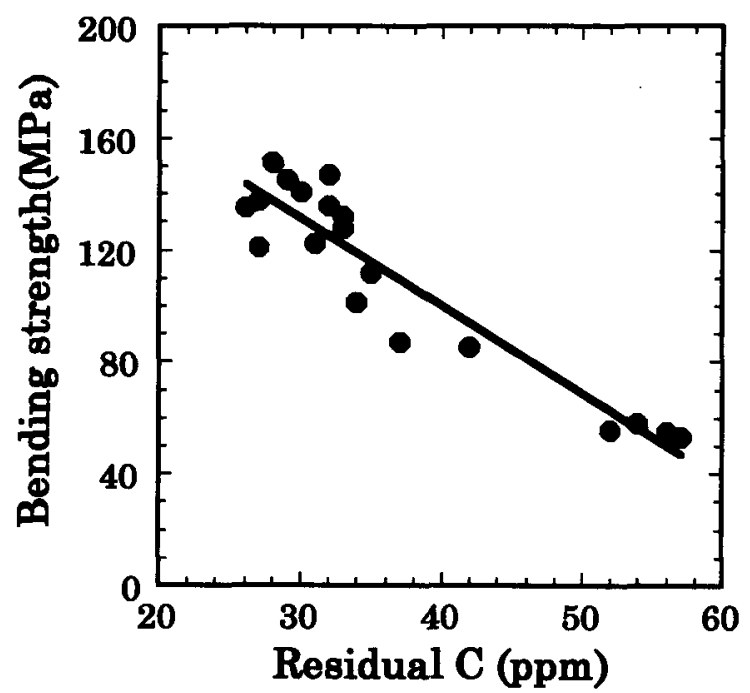

Fig.8 Relationship between bending strength and residual $\mathrm{C}$ of sintered MnZn ferrites.

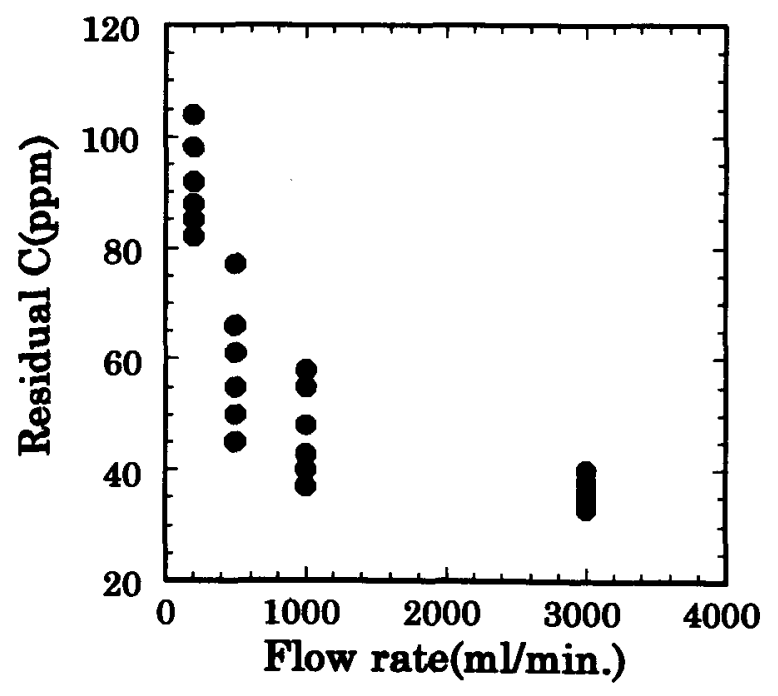

Fig.9 Relationship between an air flow rate during sintering process and residual $\mathrm{C}$ contents of sintered $\mathrm{MgCuZn}$ ferrites. 
焼結体中の残留カーボンは顆粒作製時に用いたPVAが残留 したものと考えられる.そこで焼成時のAir流量と残留カーボ ン量の関係を Fig.9に示す. Air 流量が少ないほど残留カーボ ン量が多いことが分かる。この結果から残留カーボン量が多 いサンプルは脱バインダー時にクラックが入り，そのため曲 げ強度が低下した可能性が考えられた。しかしながら Fig.3に 示したように微細構造観察において焼結体にクラックは観察 されなかった。現在のところ残留かーボン量が多いことによ り曲げ強度が低くなる知見は得られたものの微細構造・組成 分布なとにには大きな違いが見られていない，結晶粒界の構造 解析などミクロな領域での解析が今後の課題であると考えら れる。

$$
4 \text { ま と め }
$$

$\mathrm{MgCuZn}$ フェライト, $\mathrm{NiCuZn}$ フェライトおよび $\mathrm{MnZn}$ フェ ライト焼結体の微細構造要素と機械的強度の関係を調べる過 程において以下のことが明らかとなった。

(1) 狫結密度およひ粒径が同等であっても焼結体中の残留力ー ボン量が多いと曲げ強度が低下する。

(2) 残留カーボン量を制御することにより高強度のフェライト が得られる。

\section{文献}

1）阿部弘, 川合実, 营野隆志, 鉿木恵一朗: エンジニアリング セラミックス，技報堂,(1984)80。

2) 平賀貞太郎, 奥谷克伸, 尾島輝彦: フェライト, 丸善,(1986) 100.

3) S.Murayama, M.Kumagai and Y.Ikeda: "High-strength $\mathrm{NiCuZn}$ ferrite for surface mount device", Proceeding of International Conference on Ferrites, (1992)366-369.

4) K.Hirota, Y.Fujimoto, K.Watanabe and M.Sugimura: "High-B and $\mu \mathrm{MnZn}$ ferrite with improved mechanical strength", Adv. Ceram., 15(1985)385-392.

5) 日本セラミックス協会編: セラミック先端材料,オーム社, (1991)260.

6) セラミックス編集委員会基礎工学講座小委員会編 : セラ ミックスの製造プロセス,日本セラミックス協会,(1984)184.

7) 佐藤值義, 野村武史: "MnZn フェライトの顆粒の強度と磁 気特性の関係 ", 粉体および粉末治金, 42(1995)1108-1113.

8) B.Phillips, S.Somiya and A.Muan: "System $\mathrm{MgO}-\mathrm{Fe}_{2} \mathrm{O}_{3}$ in air", J. Am. Ceram. Soc., 44(1961)169.

9) M.A.Zinovik: "The Phase Equilibrium Diagram of the $\mathrm{CuO}$ $\mathrm{Cu}_{2} \mathrm{O}-\mathrm{Fe}_{2} \mathrm{O}_{3}-\mathrm{Fe}_{3} \mathrm{O}_{4}$ System", Rus. J. Inor. Chem., 33(1988)1543. 